\title{
Microtransplantation of Cellular Membranes From Squid Stellate Ganglion Reveals Ionotropic GABA Receptors
}

\author{
LUCA CONTI ${ }^{1,2, *, \dagger}$, AGENOR LIMON ${ }^{1,3, *, \dagger}$, ELEONORA PALMA ${ }^{2,4}$, AND \\ RICARDO MILEDI ${ }^{1,3}$ \\ ${ }^{1}$ Grass Laboratory at the Marine Biological Laboratory, 7 MBL St., Woods Hole, Massachusetts 02543; \\ ${ }^{2}$ Istituto Pasteur-Fondazione Cenci Bolognetti \& Dipartimento di Fisiologia e Farmacologia, \\ Università di Roma "Sapienza," 00185 Rome, Italy; ${ }^{3}$ Department of Neurobiology and Behavior, \\ University of California at Irvine, 2205 McGaugh Hall, Irvine, California, 92697-4550; and \\ ${ }^{4}$ San Raffaele Pisana IRCCS, Rome, Italy
}

\begin{abstract}
The squid has been the most studied cephalopod, and it has served as a very useful model for investigating the events associated with nerve impulse generation and synaptic transmission. While the physiology of squid giant axons has been extensively studied, very little is known about the distribution and function of the neurotransmitters and receptors that mediate inhibitory transmission at the synapses. In this study we investigated whether $\gamma$-aminobutyric acid (GABA) activates neurotransmitter receptors in stellate ganglia membranes. To overcome the low abundance of GABA-like mRNAs in invertebrates and the low expression of GABA in cephalopods, we used a two-electrode voltage clamp technique to determine if Xenopus laevis oocytes injected with cell membranes from squid stellate ganglia responded to GABA. Using this method, membrane patches containing proteins and ion channels from the squid's stellate ganglion were incorporated into the surface of oocytes. We demonstrated that GABA activates membrane receptors in cellular membranes isolated from squid stellate ganglia. Using the same approach, we were able to record native glutamate-evoked currents. The squid's GABA receptors showed an $\mathrm{EC}_{50}$ of $98 \mu \mathrm{mol}^{-1}$ to GABA and were inhibited by zinc $\left(\mathrm{IC}_{50}=356 \mu \mathrm{mol} \mathrm{l^{-1 }}\right)$. Interestingly, GABA receptors from the squid were only partially blocked by bicuculline. These results indicate that
\end{abstract}

\footnotetext{
Received 16 November 2012; accepted 15 January 2013.

* To whom correspondence should be addressed. E-mail: 1uca.c83@ libero.it; alimonru@uci.edu

$\dagger$ These authors contributed equally to this work.
}

the microtransplantation of native cell membranes is useful to identify and characterize scarce membrane proteins. Moreover, our data also support the role of GABA as an ionotropic neurotransmitter in cephalopods, acting through chloride-permeable membrane receptors.

\section{Introduction}

Since its description by John Zachary Young in 1938, the squid giant synapse has been extensively studied. However, little information about the neurotransmitter receptors involved in the stellate ganglion synapses or in the brain of the squid was available. Evidence indicates that glutamate is an excitatory neurotransmitter (Miledi, 1967; DeSantis et al., 1978; Eusebi et al., 1985; Corrie et al., 1993) that activates alpha-amino-3-hydroxy-5-methyl-4isoxazolepropionic acid (AMPA)-type receptors in postsynaptic terminals of the squid synapses (Messenger, 1996; Di Cosmo et al., 2006). The cloning of the glutamate receptor subunit SqGluR from the stellate ganglion of Loligo opalescens provides further support for the excitatory role of glutamate in squid (Battaglia et al., 2003). Conversely, the inhibitory neurotransmission in squid and other cephalopods is largely unexplored.

Gamma-aminobutyric acid (GABA), a major inhibitory neurotransmitter in mammals, has been found at low levels in the octopus brain (Osborne, 1971), and immunohistochemical evidence indicates that within the whole brain the presence of GABA-containing neurons is limited to certain areas (Cornwell et al., 1993). Moreover, mRNA for GABA- 
like receptors in invertebrates is also limited (Harvey et al., 1991; Darlison, 1992). Nevertheless, inhibitory mechanisms in the squid seem to be important for learning processes. For example, the experience-dependent behavior of prey capture and the escape response observed throughout development of squid is highly dependent on the inhibitory control of the giant synapse output (Preuss and Gilly, 2000). Additionally, GABA reduces the resting electrical activity of the squid statocyst (Tu and Budelmann, 2000).

Although spontaneous and evoked inhibitory synaptic potentials due to chloride fluxes have been recorded in the stellate ganglion of squids (Miledi, 1972) and in slices of the cuttlefish optic lobe (Chrachri and Williamson, 2003), so far neither the neurotransmitter mediating those potentials nor their membrane receptors have been characterized. To examine the presence of membrane receptors to GABA, we injected membrane vesicles containing neurotransmitter receptors and accessory proteins from squid's stellate ganglia into Xenopus oocytes. As previously shown (Miledi et al., 2006; Eusebi et al., 2009), membrane patches are incorporated into the oocyte's surface a few hours after injection. The main advantage of this technique is the possibility of investigating neurotransmitter receptors by using alreadyassembled receptors, without interfering with the transcriptional and transductional host machinery. In this work we demonstrate for the first time the presence of functional ionotropic GABA receptors (GABARs) in cellular membranes microtransplanted from the squid stellate ganglion to Xenopus oocytes.

\section{Materials and Methods}

\section{Microtransplantation of squid membranes}

To dissect the stellate ganglia, the squid (Doryteuthis pealei) mantle was opened and each stellate ganglion with its nerves was exposed. The stellate ganglion, which contains neuronal somatas, stellate nerves, presynaptic secondorder giant fibers, and postsynaptic third-order giant fibers, was cut out under a stereomicroscope, lifted from the mantle, and then transferred to a Falcon tube containing liquid nitrogen. The frozen samples were stored at $-70{ }^{\circ} \mathrm{C}$ until the membranes were prepared. This preparation contains, in addition to the neuronal somatas and nerve fibers mentioned above, the connective tissue capsule surrounding the ganglion.

Membranes for oocyte injection were prepared as previously described (Miledi et al., 2006). Tissue from squids was homogenized in ice-cold buffer ( $\mathrm{pH} 9.0$ ) with 200 mmol $1^{-1}$ glycine, $150 \mathrm{mmol}^{-1} \mathrm{NaCl}, 50 \mathrm{mmol}^{-1}$ EDTA, $50 \mathrm{mmol} 1^{-1}$ EGTA, and $300 \mathrm{mmol} 1^{-1}$ sucrose and protease inhibitors (Sigma P2714; Sigma, St. Louis, MO). Samples were homogenized with an electric rotor and centrifuged at $9500 \times g$ for $15 \min \left(4{ }^{\circ} \mathrm{C}\right)$. The supernatant was ultracentrifuged in a Beckman SW41 rotor at 100,000 $\times g$ for $2 \mathrm{~h}$ at $4{ }^{\circ} \mathrm{C}$. The resultant pellet was resuspended in sterile distilled water and stored at $-70{ }^{\circ} \mathrm{C}$. Stage V-VI Xenopus oocytes were injected with $50 \mathrm{nl}$ of a membrane preparation. Injected oocytes were kept in Barth's solution $\left[88 \mathrm{mmol} \mathrm{l}^{-1} \mathrm{NaCl}, 0.33 \mathrm{mmol} \mathrm{l}^{-1} \mathrm{Ca}\left(\mathrm{NO}_{3}\right)_{2}, 0.41 \mathrm{mmol}\right.$ $1^{-1} \mathrm{CaCl}_{2}, 1 \mathrm{mmol} \mathrm{l}^{-1} \mathrm{KCl}, 0.82 \mathrm{mmol} \mathrm{l}^{-1} \mathrm{MgSO}_{4}, 2.4$ mmol $1^{-1} \mathrm{NaHCO}_{3}, 10 \mathrm{mmol} 1^{-1}$ HEPES (pH 7.4)] at $16-17{ }^{\circ} \mathrm{C}$ until the moment of recording.

\section{Electrophysiology}

After 12 to $48 \mathrm{~h}$ postinjection, membrane currents were recorded from voltage-clamped oocytes using two microelectrodes filled with $3 \mathrm{~mol} \mathrm{l}^{-1} \mathrm{KCl}$ and continuously perfused with oocyte Ringer's solution (Miledi, 1982). Solution exchange was achieved by using electromagnetic valves and a computer-controlled perfusion system (Warner Instruments).

Current-voltage $(I-V)$ relationships were constructed holding the oocytes at $-70 \mathrm{mV}$ and stepping the membrane potential for 2-4 min to the desired value before applying 1 mmol $\mathrm{l}^{-1}$ GABA. To determine the equilibrium potential for GABA ( $\left.\mathrm{E}_{\mathrm{GABA}}\right)$ a second-order polynomial curve was fitted to $I-V$ relationships (pClamp 10). All results are given as mean \pm S.E.M. Two data sets were considered statistically different when $P<0.05$ (ANOVA).

\section{Chemicals and solutions}

Oocyte Ringer's solution (OR) had the following composition (in mmol ${ }^{-1}$ ): $\mathrm{NaCl} 82.5 ; \mathrm{KCl} 2.5 ; \mathrm{CaCl}_{2} 2.5$; $\mathrm{MgCl}_{2} 1$; HEPES 5, adjusted to $\mathrm{pH} 7.4$ with $\mathrm{NaOH}$. Kainic acid, 2-amino-3-(5-methyl-3-oxo-1,2-oxazol-4-yl), propanoic acid (AMPA), and cyclothiazide (CTZ) were purchased from Tocris Biosciences (UK). GABA and bicuculline were purchased from Sigma (St. Louis, MO). $\mathrm{ZnCl}_{2}$ was purchased from Fisher Scientific (Fair Lawn, NJ). GABA, AMPA, and bicuculline were dissolved in bidistilled water. CTZ was dissolved to $100 \mathrm{mmol} \mathrm{l}^{-1}$ in DMSO. The $\mathrm{ZnCl}_{2}$ stock solution was prepared by serial dilutions with bidistilled water of a solution containing $100 \mathrm{mmol} \mathrm{l}^{-1}$ $\mathrm{ZnCl}_{2}$ and $10 \mathrm{mmol} \mathrm{l}^{-1} \mathrm{HCl}$ (Paoletti et al., 1997) and the $\mathrm{pH}$ adjusted to 7.4 in the final solution. The concentrated stock solutions were dissolved in OR prior to use.

\section{Results}

GABA and glutamate receptors in the stellate ganglion of squid

We applied $1 \mathrm{mmol} \mathrm{l}^{-1}$ GABA to oocytes not injected with membranes from squid stellate ganglia, and the lack of responses to GABA in these oocytes confirmed that native Xenopus oocytes do not express endogenous GABARs (Fig. $1 \mathrm{~A})$. In contrast, $80 \%$ of all the oocytes injected with the membranes elicited GABA-activated currents $\left(\mathrm{I}_{\mathrm{GABA}}\right)$ of 
A

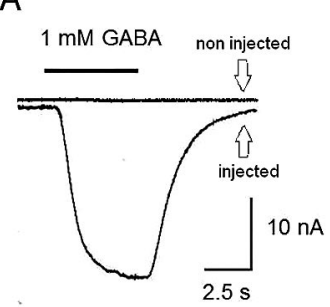

B

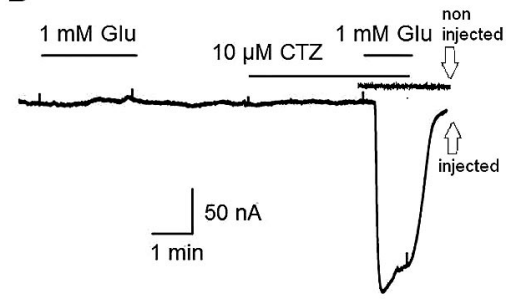

Figure 1. GABA and glutamate receptors from squid stellate ganglia. Current traces of responses to $1 \mathrm{mmol}^{-1} \mathrm{GABA}$ and to $1 \mathrm{mmol}^{-1}$ glutamate plus $10 \mu \mathrm{mol}^{-1}$ cyclothiazide (CTZ) of an oocyte injected with cellular membranes isolated from squid stellate ganglia. Superimposed: GABA or glutamate responses in non-injected oocytes. Bars indicate the perfusion time of the agonists.

$-48.3 \pm 18.0 \mathrm{nA}$ (range -2.7 to $-106.8 \mathrm{nA}$ ), clearly indicating that squids express ionotropic GABARs that were successfully transplanted to Xenopus oocytes (Fig. 1A). The activation of $\mathrm{I}_{\mathrm{GABA}}$ was adjusted with a time constant of $1.9 \pm 0.4 \mathrm{~s}(n=19)$. Interestingly, $\mathrm{I}_{\mathrm{GABA}}$ showed little desensitization at maximal concentrations of GABA. The oocytes that exhibited $\mathrm{I}_{\mathrm{GABA}}$ also responded to $100 \mu \mathrm{mol} \mathrm{l}^{-1}$ kainate, an agonist of ionotropic glutamate receptors (GluRs). However, $1 \mathrm{mmol} \mathrm{l}^{-1}$ glutamate did not elicit responses in the same oocytes. To determine if the lack of responses to glutamate was a consequence of a fast and strong desensitization of GluRs, we co-applied $1 \mathrm{mmol} \mathrm{l}^{-1}$ glutamate with $10 \mu \mathrm{mol} \mathrm{l}{ }^{-1} \mathrm{CTZ}$, the latter a compound that stabilizes the non-desensitized state of AMPA-type receptors. In these conditions glutamate elicited non-desensitizing responses of $-10.4 \pm 5.1 \mathrm{nA}$ (range -3.0 to $-20.8 \mathrm{nA}$, $n=8$; Fig. 1B). Similar non-desensitizing currents were observed with co-application of $50 \mu \mathrm{mol} \mathrm{l}^{-1}$ AMPA and 20 $\mu \mathrm{mol} 1^{-1}$ CTZ $(-22.9 \pm 7.3 \mathrm{nA}, n=7)$. The potentiation of glutamate currents by CTZ indicates that the kinetic properties of glutamate receptors from the stellate ganglion are quite different from those of ionotropic receptors activated by GABA, which showed a limited level of desensitization. No responses to $1 \mathrm{mmol} \mathrm{l}^{-1}$ glycine $(n=6)$ or $1 \mathrm{mmol} \mathrm{l}^{-1}$ carbachol $(n=30)$, the latter an agonist of ionotropic and metabotropic cholinergic receptors, were detected in oocytes injected with membranes from the squid stellate ganglia.

\section{Physiological properties of GABARs from the squid stellate ganglion}

We further characterized GABARs from squid stellate ganglia. The perfusion of $1 \mathrm{mmol}^{-1}$ GABA to microtransplanted oocytes held at different voltages was used to determine the current-voltage $(I-V)$ relationship of $\mathrm{I}_{\mathrm{GABA}}$. The current inverted its polarity at $-18.3 \pm 0.9 \mathrm{mV}(n=6$, Fig. 2 ), a value near the predicted equilibrium potential of chloride of $-26 \mathrm{mV}$ in Xenopus oocytes, with an external chlo-

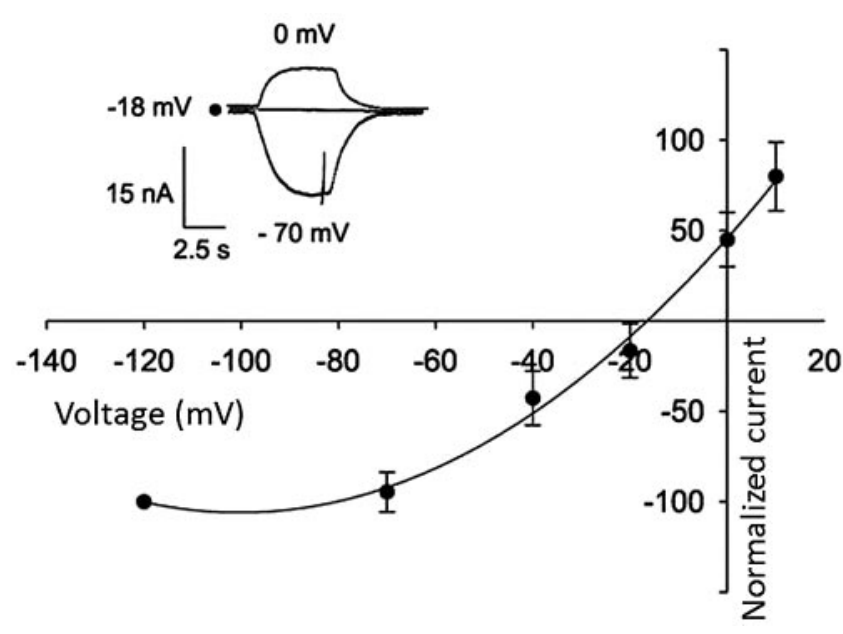

Figure 2. Reversal potential of GABA-evoked current. Current-voltage $(I-V)$ relationship from oocytes injected with membranes of stellate ganglia of squids. Points represent means ( \pm SEM) of peak GABA currents that inverted at $-18.3 \pm 0.9 \mathrm{mV}$ ( 6 oocytes, 2 frogs, 30 squids). The GABA concentration applied was $1 \mathrm{mmol}^{-1}$. Currents were normalized to those induced at $-120 \mathrm{mV}$ (average of GABA currents $=-21.7 \pm$ $9.8 \mathrm{nA}, 6$ oocytes, 2 frogs, 30 squids). Note the strong GABA current rectification at very negative potentials.

ride concentration of $92 \mathrm{mmol}^{-1}$ (Ringer's in this study) and an internal concentration of $33.4 \mathrm{mmol}^{-1}$ (Barish, 1983). This result indicates that chloride is the main carrier of $\mathrm{I}_{\mathrm{GABA}}$. The apparent affinity of GABARs for GABA was calculated from concentration response curves. Application of each concentration of GABA was done every $5 \mathrm{~min}$ to allow for full recovery of the response. $\mathrm{I}_{\mathrm{GABA}}$ had $\mathrm{EC}_{50}$ and $\mathrm{n}_{\mathrm{H}}$ values of $98.0 \pm 0.7 \mu \mathrm{mol} \mathrm{l} \mathrm{l}^{-1}$ and $1.5 \pm 0.1$ (8 oocytes, 2 frogs, 30 squids; Fig. 3). GABARs were reversibly inhibited by $\mathrm{Zn}^{2+}$ in a concentration-dependent manner. The $\mathrm{IC}_{50}$ of $\mathrm{Zn}^{2+}$ on $\mathrm{I}_{\mathrm{GABA}}$, elicited by $250 \mu \mathrm{mol} \mathrm{l}^{-1}\left(\mathrm{EC}_{80}\right.$ value for GABA), was $356 \pm 6 \mu \mathrm{mol} 1^{-1}$ (10 oocytes, 2 frogs, 30 squids; Fig. 4). We also examined the effects of $100 \mu \mathrm{mol} 1^{-1}$ bicuculline, a competitive antagonist of $\mathrm{GABA}_{\mathrm{A}}$ receptors, in batches of oocytes from two different frogs. Interestingly, bicuculline reduced the maximum amplitude of $\mathrm{I}_{\mathrm{GABA}}$ by $23 \%$, from $-64.4 \pm 14.7 \mathrm{nA}$ to $51.5 \pm$ $11.7 \mathrm{nA}$. The reduction in the amplitude of $\mathrm{I}_{\mathrm{GABA}}$ by bicuculline did not affect the temporal course of the activation or the level of desensitization of $\mathrm{I}_{\mathrm{GABA}}$ (6 oocytes, 2 frogs; data not shown).

\section{Discussion}

Since no information about the GABA receptors in squid is available and mRNAs of GABA-like subunits are at very low abundance in invertebrates (Harvey et al., 1991; Darlison, 1992), we used the method of microtransplantation of cell membranes to determine the presence of GABARs in the squid stellate ganglia. This method has been used suc- 


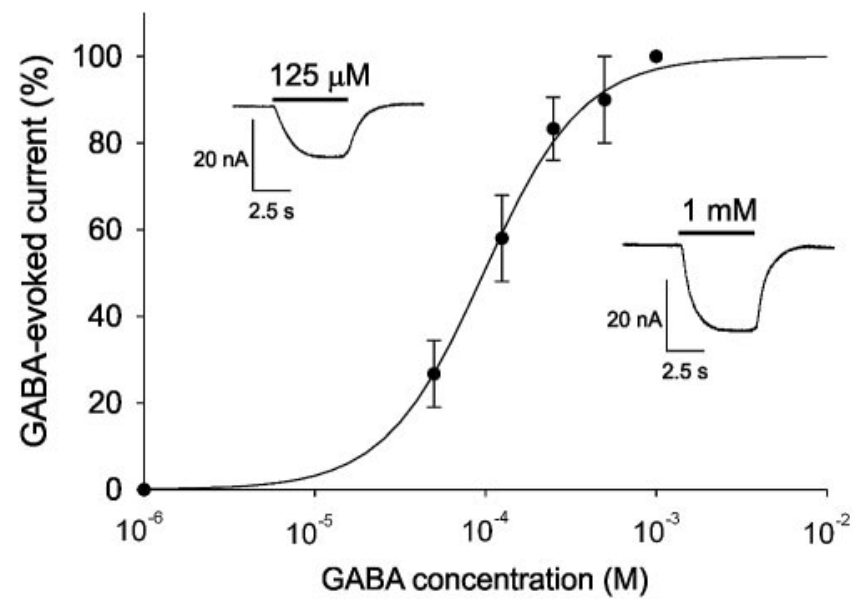

Figure 3. Concentration-dependent responses of squid GABA receptors. Log dose-response curve showing peak GABA currents versus GABA concentrations, fitted using the Hill equation. The parameters fitted by least squares analysis were $\mathrm{EC}_{50}=98.0 \pm 0.7 \mu \mathrm{mol} \mathrm{l}^{-1}$ and $\mathrm{n}_{\mathrm{H}}=1.5 \pm$ 0.1 . The average of peak GABA $\left(1 \mathrm{mmol} 1^{-1}\right)$-currents was $-65.3 \pm 9.6 \mathrm{nA}$ ( 8 oocytes, 2 frogs, 30 squids). Points represent means ( \pm SEM).

cessfully in different species, from Torpedo fish to human, but it had not been tried on the nervous system of an invertebrate organism (Marsal et al., 1995; Miledi et al., 2002; Palma et al., 2005; Limon et al., 2008; Eusebi et al., 2009). In this study we show that squid membranes were able to fuse into the oocyte's membrane, and as evidenced by ion currents elicited by glutamate and GABA, squids express native ionotropic GluRs and GABARs.

Squid GluRs displayed a strong desensitization to glutamate that was removed by cyclothiazide (CTZ), which is a

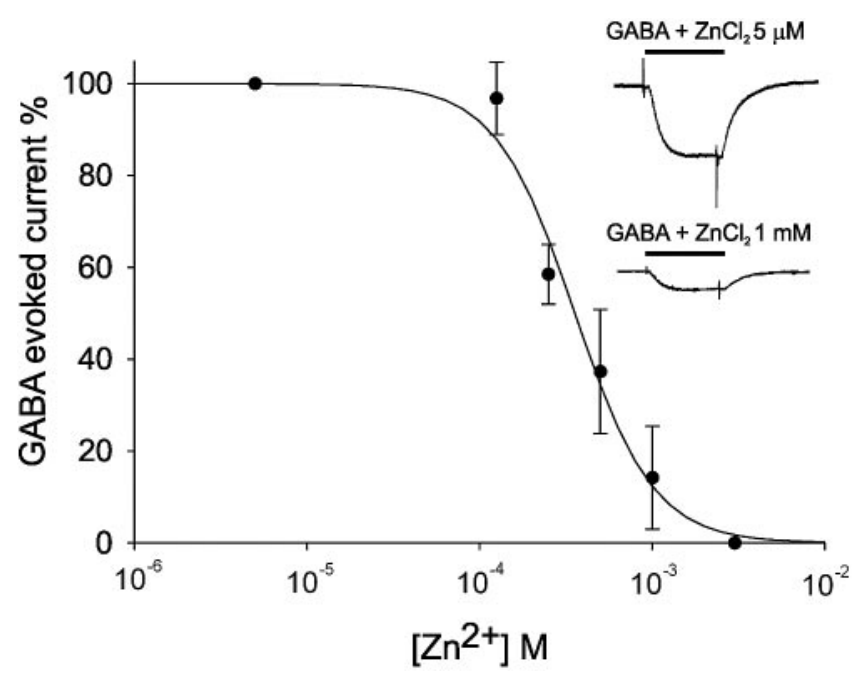

Figure 4. Squid GABA receptors are sensitive to zinc. Currents evoked by $250 \mu \mathrm{mol} 1^{-1}$ GABA co-applied with different $\mathrm{Zn}^{2+}$ concentrations in oocytes injected with squid stellate ganglion (6 oocytes, 2 frogs, 50 squids). Data were fitted by least squares analysis, giving $\mathrm{IC}_{50}=356 \pm$ $6 \mu \mathrm{mol} \mathrm{l}^{-1}$. Points represent means ( \pm SEM). compound that stabilizes the non-desensitized state of AMPA receptors in vertebrates (Partin et al., 1994). The potentiation of glutamate currents by CTZ suggests that SqGluR, with a $44 \%-46 \%$ amino acid identity to the mammalian AMPA-subunits GluR1-GluR4, is the subunit making up the native glutamate receptors (Battaglia et al., 2003).

While glutamate in squid has an excitatory role, it is not known which neurotransmitter is responsible for the inhibitory modulation in the squid or in cephalopods in general. Given that cephalopods are considered to be the more advanced invertebrates in problem-solving tests, it is important to determine which components maintain the excitatory-inhibitory balance in the cephalopod nervous system. Hyperpolarizing potentials have been described in the squid stellate ganglion (Miledi, 1972), in secondary hair cells and afferent neurons of the squid statocyst (Williamson, 1989), and in central neurons of the cuttlefish (Chrachri and Williamson, 2003). In our experiments, native receptors elicited GABA currents that were carried by chloride. In squid, the extracellular chloride concentration $[\mathrm{Cl}]_{\mathrm{o}}$ is near $560 \mathrm{mmol}$ $1^{-1}$ (Hodgkin, 1951), and the internal concentration $[\mathrm{Cl}]_{i}$ varies between $41 \mathrm{mmol} \mathrm{l}^{-1}$ (Steinbach, 1941) and 150 $\mathrm{mmol} \mathrm{l}^{-1}$ (Keynes, 1963); therefore the equilibrium potential for chloride, and consequently the polarity of the potentials elicited by chloride fluxes, may vary over a wide range. However, it is important to note that the inversion potential for chloride is near the resting membrane potential of squid axons, suggesting that chloride is the main carrier of inhibitory currents (Miledi, 1972). Moreover, in those experiments, hyperpolarizing potentials frequently reversed sign minutes after cells were impaled with $\mathrm{KCl}$-filled electrodes; when cells were impaled with electrodes filled with $\mathrm{K}$ citrate, the reversal of sign was slower (Miledi, 1972). Although it cannot be discounted that GABA may be excitatory under certain circumstances, it is highly probable that chloride-permeable GABA receptors are the molecular basis of hyperpolarizing potentials in squid synapses.

Native GABA receptors from the squid were less sensitive $\left(\mathrm{EC}_{50}\right.$ of $98 \mu \mathrm{mol} \mathrm{l^{-1 }}$ ) than homomeric GABA receptors composed of the $R d l$ subunit from the fruit fly $\left(\mathrm{EC}_{50}\right.$ between 10 and $50 \mu \mathrm{mol} \mathrm{l}^{-1}$; Ffrench-Constant et al., 1993); but similar to the sensitivity of receptors composed by one of the $R d l$ splice variants $\left(\mathrm{EC}_{50}\right.$ of $152 \mu \mathrm{mol} \mathrm{1^{-1 }}$; Belelli et al., 1996). Interestingly, native receptors from the squid were more sensitive than the heterologously expressed GABARs of the pond snail Lymnaea stagnalis (EC 50 200-300 $\mu \mathrm{mol} \mathrm{1}{ }^{-1}$; Harvey et al., 1991), a mollusc that is phylogenetically closer to cephalopods than the fruit fly and that expresses a transmembrane protein with about $50 \%$ identity to vertebrate $\mathrm{GABA}_{\mathrm{A}}$ receptor $\beta$ subunits (Harvey et al., 1991). Among the cephalopods there is evidence that the cuttlefish expresses an mRNA (Q9GYU4_Uniprot; Kirby et al., 1997) that would produce 
a protein with an identity of $66 \%$ with the $\mathrm{GABA}_{\mathrm{A}} \mathrm{R} \beta$-like subunit in the pond snail, of $61 \%$ with the $\mathrm{GABA}_{\mathrm{A}} \mathrm{R} \beta$-like subunit Lcch3 in the fruit fly, and of $48 \%$ with GABRB1 in human. However, it is not known if this protein from the cuttlefish will produce functional homomeric GABA receptors, or if it will require a heteromeric assembly with another as yet unidentified subunit to make functional channels. In this regard, the microtransplantation method provides a strong experimental platform for study of the properties of native GABA receptors still embedded in their own membranes. An initial exploration of the pharmacological profile of native squid GABA receptors showed that squid GABA receptors were sensitive to $\mathrm{Zn}^{2+}$, similarly to GABA receptors from some invertebrates (Smart and Constanti, 1982) and to all GABA receptors in vertebrates (Hosie et al., 2003). Interestingly, the $\mathrm{IC}_{50}$ for $\mathrm{Zn}^{2+}$ in squid GABARs $\left(356 \mu \mathrm{mol} 1^{-1}\right)$ is closer to that of $\mathrm{GABA}_{\mathrm{A}} \mathrm{Rs}$ containing a $\gamma$ subunit that show a lower affinity for $\mathrm{Zn}^{2+}$ than the receptors lacking the $\gamma$ subunit but with high affinity for $\mathrm{Zn}^{2+}$ (Hosie et al., 2003; Palma et al., 2007). Additionally, squid GABA receptors were only partially blocked by bicuculline, similar to GABA receptors in invertebrates (Lunt, 1991) and the vertebrate GABARs composed by $\rho$ subunits (Polenzani et al., 1991) in vertebrates. Future experiments using molecular biology approaches on squid stellate ganglion will be useful to identify the GABAR subunit involved in the inhibitory transmission in invertebrates. The pharmacological and biophysic properties of native GABARs and their comparison with other invertebrate and vertebrates GABAARs merit further studies.

\section{Acknowledgments}

This work is dedicated to the memory of Matilde. All the data were acquired at the Marine Biological Laboratory in Woods Hole thanks to the Grass Foundation Fellowships to L.C. and A.L. (www.grassfoundation.org). L.C. was additionally supported by the Ph.D. in Neurophysiology program of the University of Rome "La Sapienza." All authors were Grass Fellows. This work was supported by Ministero della Sanità Antidoping and PRIN project 2009 (to E.P.). We would like to thank, in particular, Professors Felix E. Schweizer and Stephanie White for the help with dissections.

\section{Literature Cited}

Barish, M. E. 1983. A transient calcium-dependent chloride current in the immature Xenopus oocyte. J. Physiol. 342: 309-325.

Battaglia, A. A., G. Nardi, A. Steinhardt, A. Novakovic, S. Gentile, P. Iaccarino Idelson, W. F. Gilly, and A. de Santis. 2003. Cloning and characterization of an ionotropic glutamate receptor subunit expressed in the squid nervous system. Eur. J. Neurosci. 17: 2256-2266.

Belelli, D., H. Callachan, C. Hill-Venning, J. A. Peters, and J. J. Lambert. 1996. Interaction of positive allosteric modulators with human and Drosophila recombinant GABA receptors expressed in Xenopus laevis oocytes. Br. J. Pharmacol. 118: 563-576.

Chrachri, A., and R. Williamson. 2003. Modulation of spontaneous and evoked EPSCs and IPSCs in optic lobe neurons of cuttlefish Sepia officinalis by the neuropeptide FMRF-amide. Eur. J. Neurosci. 17: 526-536.

Cornwell, C. J., J. B. Messenger, and R. Williamson. 1993. Distribution of GABA-like immunoreactivity in the octopus brain. Brain Res. 621: 353-357.

Corrie, J. E., A. DeSantis, Y. Katayama, K. Khodakhah, J. B. Messenger, D. C. Ogden, and D. R. Trentham. 1993. Postsynaptic activation at the squid giant synapse by photolytic release of L-glutamate from a 'caged' L-glutamate. J. Physiol. 465:1-8.

Darlison, M. G. 1992. Invertebrate GABA and glutamate receptors: molecular biology reveals predictable structures but some unusual pharmacologies. Trends Neurosci. 15: 469-474.

DeSantis, A., F. Eusebi, and R. Miledi. 1978. Kainic acid and synaptic transmission in the stellate ganglion of the squid. Proc. R. Soc. Lond. B Biol. Sci. 202: 527-532.

Di Cosmo, A., C. Di Cristo, and J. Messenger. 2006. L-glutamate and its ionotropic receptors in the nervous system of cephalopods. Curr. Neuropharmacol. 4: 305-312.

Eusebi, F., R. Miledi, I. Parker, and J. Stinnakre. 1985. Post-synaptic calcium influx at the giant synapse of the squid during activation by glutamate. J. Physiol. 369: 183-197.

Eusebi, F., E. Palma, M. Amici, and R. Miledi. 2009. Microtransplantation of ligand-gated receptor-channels from fresh or frozen nervous tissue into Xenopus oocytes: a potent tool for expanding functional information. Prog. Neurobiol. 88: 32-40.

Ffrench-Constant, R. H., T. A. Rocheleau, J. C. Steichen, and A. E. Chalmers. 1993. A point mutation in a Drosophila GABA receptor confers insecticide resistance. Nature 363: 449-451.

Harvey, R. J., E. Vreugdenhil, S. H. Zaman, N. S. Bhandal, P. N. Usherwood, E. A. Barnard, and M. G. Darlison. 1991. Sequence of a functional invertebrate GABAA receptor subunit which can form a chimeric receptor with a vertebrate alpha subunit. EMBO J. 10: 3239-3245.

Hodgkin, A. L. 1951. The ionic basis of electrical activity in nerve and muscle. Biol. Rev. 26: 339-409.

Hosie, A. M., E. L. Dunne, R. J. Harvey, and T. G. Smart. 2003. Zinc-mediated inhibition of $\mathrm{GABA}_{\mathrm{A}}$ receptors: discrete binding sites underlie subtype specificity. Nat. Neurosci. 6: 362-369.

Keynes, R. D. 1963. Chloride in the squid giant axon. J, Physiol. 169: 690-705.

Kirby, R. R., R. Williamson, and S. Farley. 1997. GABA-A receptor gene sequence from the central nervous system of the cuttlefish, Sepia officinalis. Soc. Neurosci. Abstr. 23: 957-957.

Limon, A., J. M. Reyes-Ruiz, and R. Miledi. 2008. Microtransplantation of neurotransmitter receptors from postmortem autistic brains to Xenopus oocytes. Proc. Natl. Acad. Sci. USA 105: 10973-10977.

Lunt, G. G. 1991. GABA and GABA receptors in invertebrates. Semin. Neurosci. 3: 251-258.

Marsal. J., G. Tigyi, and R. Miledi. 1995. Incorporation of acetylcholine receptors and $\mathrm{Cl}^{-}$channels in Xenopus oocytes injected with Torpedo electroplaque membranes. Proc. Natl. Acad. Sci. USA 92: 5224-5228.

Messenger, J. B. 1996. Neurotransmitters of cephalopods. Invert. Neurosci. 2: 95-114.

Miledi, R. 1967. Spontaneous synaptic potentials and quantal release of transmitter in the stellate ganglion of the squid. J. Physiol. 192: 379-406.

Miledi, R. 1972. Synaptic potentials in nerve cells of the stellate ganglion of the squid. J. Physiol. 225: 501-514. 
Miledi, R. 1982. A calcium-dependent transient outward current in $\mathrm{Xe}$ nopus laevis oocytes. Proc. R. Soc. Lond. B Biol. Sci. 215: 491-497.

Miledi, R., F. Eusebi, A. Martínez-Torres, E. Palma, and F. Trettel. 2002. Expression of functional neurotransmitter receptors in Xenopus oocytes after injection of human brain membranes. Proc. Natl. Acad. Sci. USA 99: 13238-13242.

Miledi, R., E. Palma, and F. Eusebi. 2006. Microtransplantation of neurotransmitter receptors from cells to Xenopus oocyte membranes: new procedure for ion channel studies. Methods Mol. Biol. 322: 347355.

Osborne, N. N. 1971. Occurrence of GABA and taurine in the nervous systems of the dogfish and some invertebrates. Comp. Gen. Pharmacol. 2: $433-438$.

Palma, E., G. Spinelli, G. Torchia, A. Martinez-Torres, D. Ragozzino, R. Miledi, and F. Eusebi. 2005. Abnormal GABAA receptors from the human epileptic hippocampal subiculum microtransplanted to Xenopus oocytes. Proc. Natl. Acad. Sci. USA 102: 2514-2518.

Palma, E., C. Roseti, F. Maiolino, S. Fucile, K. Martinello, M. Mazzuferi, E. Aronica, M. Manfredi, V. Esposito, G. Cantore et al. 2007. $\mathrm{GABA}_{\mathrm{A}}$-current rundown of temporal lobe epilepsy is associated with repetitive activation of $\mathrm{GABA}_{\mathrm{A}}$ "phasic" receptors. Proc. Natl. Acad. Sci. USA 104: 20944-20948.

Paoletti, P., P. Ascher, and J. Neyton. 1997. High-affinity zinc inhibition of NMDA NR1-NR2A receptors. J. Neurosci. 17: 5711-5725.
Partin, K. M, D. K. Patneau, and M. L. Mayer. 1994. Cyclothiazide differentially modulates desensitization of alpha-amino-3-hydroxy-5methyl-4-isoxazolepropionic acid receptor splice variants. Mol. Pharmacol. 46: 129-138.

Polenzani, L., R. M. Woodward, and R. Miledi. 1991. Expression of mammalian gamma-aminobutyric acid receptors with distinct pharmacology in Xenopus oocytes. Proc. Natl. Acad. Sci USA 88: 4318-4322.

Preuss, T., and W. F. Gilly. 2000. Role of prey-capture experience in the development of the escape response in the squid Loligo opalescens: a physiological correlate in an identified neuron. J. Exp. Biol. 203: $559-565$

Smart, T. G., and A. Constanti. 1982. A novel effect of zinc on the lobster muscle GABA receptor. Proc. R. Soc. Lond. B Biol. Sci. 215: 327-341.

Steinbach, H. B. 1941. Chloride in the giant axons of the squid. J. Cell. Comp. Physiol. 17: 57-64.

Tu, Y., and B. U. Budelmann. 2000. Effects of nitric oxide donors on the afferent resting activity in the cephalopod statocyst. Brain Res. 865: 211-220.

Williamson, R. 1989. Secondary hair cells and afferent neurones of the squid statocyst receive both inhibitory and excitatory efferent inputs. J. Comp. Physiol. A 165: 847-860.

Young, J. Z. 1938. The functioning of the giant nerve fibres of the squid. J. Exp. Biol. 15: 170-185. 